\title{
I ENCONTRO SOBRE GESTÃO PARTICIPATIVA NA EDUCAÇÃO BÁSICA IFPI/CAMPUS FLORIANO E ESCOLAS PARCEIRAS
}

\section{ENCUENTRO SOBRE GESTIÓN PARTICIPATIVA EM EDUCACIÓN BÁSICA IFPI/CAMPUS FLORIANO Y PARTNER SCHOOLS}

\section{MEETING ON PARTICIPATORY MANAGEMENT IN BASIC EDUCATION IFPI / CAMPUS FLORIANO AND PARTNER SCHOOLS}

\section{Vinícius da Luz Silva ${ }^{1 ;}$ Ana Raionara e Silva Tavares²; Francisca Tannyery da Silva Nascimento $^{3 ;}$ Roniê Ferreira Roza ${ }^{4 ;}$ Sebastiana Ceci Sousa ${ }^{5}$.}

DOI: $\underline{\text { https://doi.org/10.31692/978-65-991061-3-2.114-117 }}$

\section{INTRODUÇÃO}

Este texto tem por objetivo relatar uma experiência de formação continuada em serviço que envolveu a equipe organizadora do "I Encontro sobre gestão participativa na educação básica IFPI/campus Floriano e escolas parceiras”, que ocorreu no Instituto Federal de Educação, Ciências e Tecnologia do Piauí, localizado no bairro Meladão em Floriano, ação em comemoração aos vinte e cinco anos de instituição como o tema "Educação que transforma vidas". Foram convidados professores e monitores da referida instituição, informados dos objetivos e finalidades do projeto, em seguida foram convidados gestores da rede municipal e estadual de educação da referente cidade e circunvizinha, tais carecem de cursos que venham aprimorar a prática da gestão participativa no âmbito educacional.

O conhecimento prévio dessa realidade possibilitou buscar mecanismos possíveis para auxiliar a intencionalidade da nossa prática pedagógica, possibilitando uma maneira de trabalhar a redefinição da visão sobre a prática da gestão e ampliá-lo no que se pretende compreender sobre a gestão participativa. As ações do ESGPEB abordaram quatro eixos; a) Dimensões: Administrativa e Financeira; b) Gestão Escolar: aspectos legais, registros e documentos escolares; c) Gestão Pedagógica; d) Tecnologias aplicadas à educação; e por fim a socialização da mesa redonda. A formação continuada de gestores com ênfase na gestão ocorreu nos dias 08 e 09 de agosto do ano de 2019, direcionado aos gestores da rede Municipal e Estadual, contou com a participação de 53 gestores, que estiveram presentes no auditório do IFPI/Campus Floriano com carga horária de $16 \mathrm{~h}$.

\footnotetext{
${ }^{1}$ Licenciatura em Ciências Biológicas, Instituto Federal do Piauí, vinicius77luz@ hotmail.com

${ }^{2}$ Licenciatura em Ciências Biológicas, Instituto Federal do Piauí, ronastavares12345@gmail.com

${ }^{3}$ Licenciatura em Ciências Biológicas, Instituto Federal do Piauí, tannyery@gmail.com

${ }^{4}$ Licenciatura em Ciências Biológicas, Instituto Federal do Piauí, ferreiraroza@ bol.com.br

${ }^{5}$ Doutora em Humanidades e Artes com ênfase em Educação, Instituto Federal do Piauí, sceci-sousa@ifpi.edu.br
} 
Dentre as eixos pedagógicos da gestão escolar citados foram ministrados de forma interativa por diretores e coordenadores do campus, socializando conhecimentos e experiências vivenciadas e fazendo conexão entre as redes municipal, estadual e federal de ensino.

O desenvolvimento do projeto se deu numa perspectiva dialética, dialógica, participativa e compartilhada por intermédio de intervenções com gestores de escolas municipais e estaduais, na busca de alternativas eficazes para o enfrentamento de problemáticas que emergem na realidade contemporânea educacional.

\section{RELATO DE EXPERIÊNCIA}

O "I Encontro Sobre Gestão Participativa na Educação Básica IFPI/Campus Floriano e Escolas Parceiras", teve como intuito a formação continuada de gestores, sendo composta por: administrador escolar (diretor); supervisor escolar (coordenador pedagógico) e orientador educacional, tal divisão se faz presente para uma gestão escolar mais eficiente.

Para cada cargo que foi devidamente selecionado para compor a equipe da gestão pedagógica, há uma função específica, atuando também mediante as necessidades da escola juntamente com outros demais profissionais, para que haja um real desenvolvimento qualitativo do trabalho pedagógico.

Tal projeto foi criado com embasamento nas dificuldades que são encontradas ao longo do processo da gestão escolar. Sabe-se que a maneira de gerir de modo educacional consiste em um exercício democrático, havendo assim uma necessidade de novos e mais adaptados conceitos do que realmente seria essa gestão participativa em prol da educação.

$\mathrm{O}$ atual modelo de gestão possui uma devida individualidade que "se fundamenta em objetivos educacionais representativos dos interesses das amplas camadas da população e leva em conta a especificidade do processo pedagógico escolar, processo este determinado por estes mesmos objetivos" (PARO, 1986, p. 87-8, apud, FERREIRA, 2008, p.107).

No decorrer do encontro foram pautadas, mediante aos temas do âmbito escolar, algumas necessidades como o valor do trabalho em equipe de forma harmoniosa, o convívio entre os contribuintes no processo de educação em geral, entre outros. De acordo com Libâneo (2012,p. 411):

\footnotetext{
No caso da escola, a organização e a gestão referem-se ao conjunto de normas, diretrizes, estrutura organizacional, ações e procedimentos que asseguram a racionalização do uso de recursos humanos, materiais, financeiros e intelectuais assim como a coordenação e o acompanhamento do trabalho das pessoas.
}

O encontro teve por objetivo, mostrar a verdadeira importância do gestor educacional no meio escolar, através das articulações no processo de construção de um meio onde haja 
diálogo, participação de toda uma equipe, para o melhoramento do trabalho dos profissionais e consequentemente, para o sucesso do processo educativo.

Os quatro temas trabalhados que foram abordados durante o encontro, estavam devidamente voltados à organização e ao modo de gerir o meio escolar, que puderam promover uma formação técnica política de gestores e instituições da educação básica.

A troca de conhecimentos sobre direitos e como gerir de maneira eficiente uma instituição escolar se faz, mas que necessária no ato de organização desse âmbito, de acordo com Lima (2004, p. 32) para se obter uma determinada padronização qualitativa, haveria a necessidade de uma formação eficiente do professor, salários mais justos, condições favoráveis de trabalho e de qualificação docente, gestão democrática, ampliação do período de permanência do aluno na escola, dentre outros.

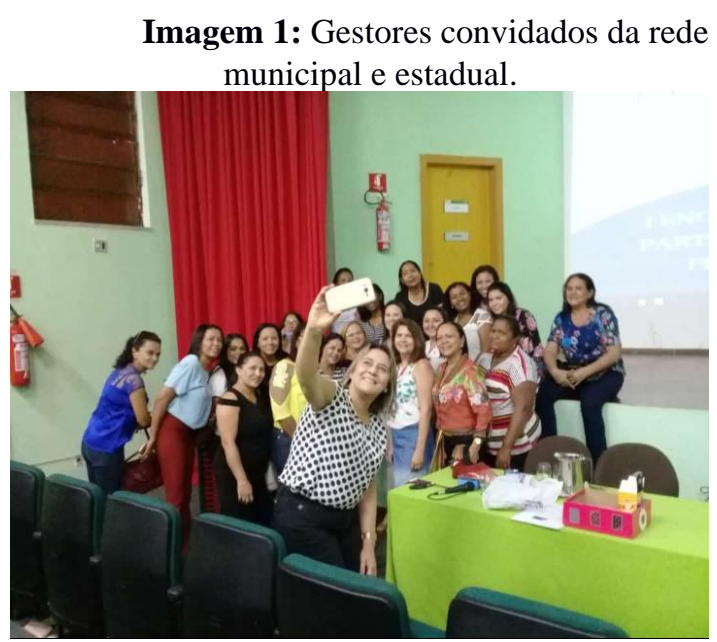

Fonte: Própria (2019).
Imagem 2: Tecnologias aplicadas a gestão escolar, ministrada pelo diretor.

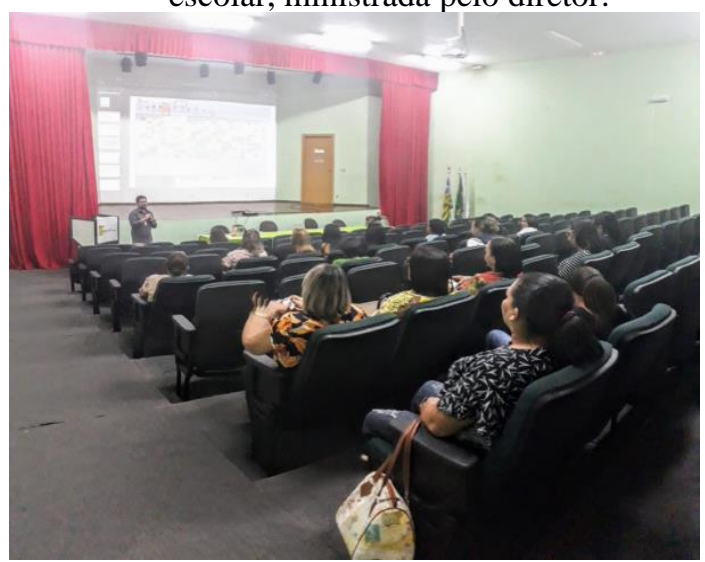

Fonte: Própria (2019).

\section{CONSIDERAÇÕES}

A execução do I Encontro sobre Gestão Participativa na Educação Básica IFPI/Campus Floriano e Escolas Parceiras contribuiu para que os participantes construam uma gestão escolar democrática, e que possam executar um projeto político pedagógico de qualidade. $\mathrm{O}$ curso de formação contínua de gestores veio a enriquecer esses profissionais para uma atuação autônoma, proporcionando aos diretores escolares uma visão global da escola, integrando as diversas disciplinas da gestão como a financeira, a pedagógica, a comunitária, tecnológica e administrativa.

O encontro mostrou-se bastante produtivo, durante os dois dias de encontro, gerando socialização de conhecimentos e experiências sobre gestão com ideias interativas e debates dinâmicos. Nesse sentido, o projeto teve a finalidade de proporcionar um novo processo de 
gestão, onde o exercício democrático se encontre como motor de um novo poder e de uma nova cultura educacional, tendo em vista a necessidade de novos e adaptados conceitos do que literalmente seria uma gestão escolar, voltado necessariamente à diretores e coordenadores de escolas, onde o valor do trabalho em equipe e de forma harmoniosa, trazem resultados positivos e imediatos para o âmbito escolar.

\section{REFERÊNCIAS}

FERREIRA, S. C. (Org.). Gestão Democrática da Educação: atuais tendências, novos desafios. 6. ed. São Paulo: Cortez, 2008.

LIBÂNEO, J. C. Educação escolar: políticas, estrutura e organização. São Paulo: Cortez, 2012.

LIMA, A. B. [org]. Estado, políticas e gestão compartilhada. São Paulo: Xamã, 2004. 